DOI: $10.52950 / E S .2021 .10 .1 .003$

\title{
PORTFOLIO CHOICE WITH A FUNDAMENTAL CRITERION - AN ALGORITHM AND PRACTICAL APPLICATIONON - A COMPUTATION METHODS AND EMPIRICAL ANALYSIS
}

\author{
PAWEL KLIBER, ANNA RUTKOWSKA-ZIARKO
}

\begin{abstract}
:
Classical models for the construction of an investment portfolio do not account for fundamental values of companies considered. In our approach, we extend the portfolio choice by adding a new criterion connected with the fundamental values of companies to the classical criteria of expected return and risk. It is assumed that an investor selects stocks according to their attractiveness, measured by some indicators of economic and financial situation of companies. In this approach, portfolios are assessed according to three criteria: their expected returns, risk (measured by variance of returns) and economic situation of the companies (measured by some indicators). In this article, we consider the book value to price ratio as a measure of the fundamental value of a company. We discuss an algorithm for constructing portfolios with this fundamental value criterion based on analytical solutions for relevant optimization problems. In the optimization problem, we consider minimizing variance with constrains on expected return and attractiveness of investment. We also present empirical examples of calculating effective portfolios of stocks listed on the Warsaw Stock Exchange and compare their performance with effective portfolios built according to the classical Markowitz approach.

By adding an additional criterion of the book to market value, we received portfolios with a higher average realized rate of return compared with the classical Markowitz model. Thus, it can be useful for investors in the capital market to incorporate an additional criterion connected with fundamental values of companies when preparing a model of stock returns.
\end{abstract}

\section{Keywords:}

portfolio analysis, fundamental value, multicriterial choice, fundamental analysis, book to market ratio

JEL Classification: C61, C63, G11

\section{Authors:}

PAWEL KLIBER, Poznan University of Economics, Poland, Email: p.kliber@ue.poznan.pl ANNA RUTKOWSKA-ZIARKO, University of Warmia and Mazury, Poland, Email: aniarek@uwm.edu.pl

\section{Citation:}

PAWEL KLIBER, ANNA RUTKOWSKA-ZIARKO (2021). Portfolio choice with a fundamental criterion - an algorithm and practical applicationon - a computation methods and empirical analysis. International Journal of Economic Sciences, Vol. X(1), pp. 39-52., 10.52950/ES.2021.10.1.003 


\section{Introduction}

Classical methods for selecting an investment portfolio, developed by Markowitz $(1952,1959)$ and Sharpe (1963), take into account only the market performance of companies, measured with changes in their prices. In the classical model, potential portfolios of investment are evaluated according to two criteria: expected return (which describes the potential level of profitability from an investment) and risk. The first criterion is measured with the expected rate of return and the second one - with the variance or standard deviation of returns. No other criteria are considered that might give some additional information about the financial standing and prospects of a company that could influence prices of its shares.

In recent years, however, there has been a growing interest in portfolio analysis methods with alternative ways of constructing portfolios. The article by Kolm, Tütüncü and Fabozzi (2014) contains a review of major developments in the portfolio theory since it its origin, and the book by Doumpos and Zopounidis (2014) draws attention to multicriteria methods used in this field. Most innovations depend on using some criteria of risk other than variance or standard deviation of returns, for example semi-variance or conditional value at risk. The article by Fabozzi, Focardi and Jonas (2007) presents a variety of risk measures that are currently used in the practice of portfolio investments. In other approaches, some characteristics of the distribution of returns on assets are used as additional criteria for evaluating portfolio performance. Examples of such characteristics can be skewness or kurtosis. Expanded portfolio analysis is presented by Briec, Kerstens and Jokund (2007) or Rodríguez, Luque and González (2011).

There are several studies which include criteria not based on returns on assets. There is a branch of the literature which takes into account ethical, social or environmental criteria in portfolio construction, for example the so-called socially responsible investments approach described in Steuer, Qi and Hirschberger (2007). The articles by Ballestero et al. (2012) and Bilbao-Terol et al. (2013) are a few more examples illustrating this approach.

Lo, Petrov and Wierzbicki (2003) considered liquidity of stocks as an additional criterion in the portfolio construction process. There are only a few papers which also take into consideration fundamental values of companies. Xidonas, Mavrotas and Psarras (2010) considered the sum of dividends paid by companies. Jacobs and Levy (2013) took into account the risk associated with leverage. The utility function of an investor includes the costs of margin calls, which can force borrowers to liquidate securities at adverse prices due to their illiquidity, losses exceeding the capital invested, and the possibility of bankruptcy.

In accordance with the theoretical concept and empirical research (Fama and French 1992, 2015, 2017; Lam 2002; Zaremba, Czapkiewicz 2017), fundamental factors are important in shaping returns on capital markets. Therefore, it seems rational to include them in a stock portfolio model. The current extensive research on the main financial markets of Eastern Europe has corroborated significant impact of fundamental information concerning companies on their rates of returns. This has also been found to hold true for the book to market ratio as an indicator of the financial standing of companies. The research sample included five countries: the Czech Republic, Hungary, Poland, Russia, and Turkey (Zaremba, Czapkiewicz 2017).

There have been several attempts to combine a portfolio analysis with the fundamental analysis of companies from the Polish stock markets. Tarczyński (2002) developed a synthetic measure to evaluate the economic and financial standing of a company, which he called the taxonomic 
measure of attractiveness of investment (TMAI), and to apply this measure as an additional criterion in the evaluation of possible portfolios. The portfolio constructed with the use of TMAI was called a fundamental portfolio. The analytical solution of this model was given by Kliber and RutkowskaZiarko (2018). This model has been modified in recent years, for example by substituting variance with semi-variance as a risk measure (Rutkowska-Ziarko and Garsztka 2014). In Rutkowska-Ziarko (2013), the Mahalanobis distance was used to determine the TMAI due to possible correlation between diagnostic financial variables. Another method was proposed by Pośpiech (2019) in the research on financial ratios, and market indicators were applied to guide the initial selection of companies. Afterwards, the classical Markowitz portfolio optimization was used.

In this article, we propose an approach in which the book to market ratio (BM) serves as a measure of the current pricing of companies in a portfolio by the capital market. We present a simple algorithm for constructing a fundamental portfolio with the book to market ratio as an additional criterion for evaluating portfolios. The algorithm is based on analytical solutions of optimization problems. In the empirical part, we verify this method by computing fundamental portfolios of the stocks traded on the Warsaw Stock Exchange. We evaluated both the mathematical side of the proposed model and its usefulness for investors. To this end, we constructed a large number of portfolios (using both classical approach and our propositions) and compared their realized rates of returns.

The article is organized as follows. After this introduction, we present in section 2 our proposal of extending the classical portfolio theory with an additional, fundamental criterion. Section 3 provides an analytical solution to the problems connected with computing fundamental portfolios and an algorithm for constructing such portfolios. Section 4 contains empirical examples from the Warsaw Stock Exchange, and section 5 concludes the research.

\section{Portfolio problem with the book to market ratio criterion}

In the article, we use generalization of the classical Markowitz model of portfolio optimization (cf. Markowitz 1952 and Markowitz 1959). We consider an investor who tries to determine optimal composition of his portfolio. Let us assume that there are $n$ risky assets with random rates of returns $R_{1}, \ldots, R_{n}$. Let $\mu_{i}$ be an expected return of asset $i: \mu_{i}=E\left[R_{i}\right]$. By $\operatorname{cov}_{i j}$ we denote covariance between the asset $i$ and $j, \operatorname{cov}_{i j}=\operatorname{cov}\left(R_{i}, R_{j}\right)$. By $x_{i}$ we denote the proportion of wealth invested in asset $i$. As in the classical Markowitz model, an investor evaluates a portfolio according to criteria of expected rate of return and risk. The expected return equals

$$
\mu_{P}=\sum_{i=1}^{n} x_{i} \mu_{i}
$$

and the risk is measured by the variance of return from the portfolio, which equals

$$
\sigma_{P}^{2}=\sum_{i=1}^{n} \sum_{j=1}^{n} x_{i} x_{j} \operatorname{cov}_{i j} .
$$

The expected return and the variance of return of the portfolio's components are estimated on the basis of historical returns of the companies' shares. Thus, the problem of portfolio selection relies entirely on the past market data. In our approach, we combine this classical approach to estimating future market performance with the fundamental analysis. It augments the Markowitz model with a third criterion, which describes financial and economic standing of companies whose shares are in the portfolio. 
Market multiples are financial indicators that compare given accounting values per share with the market price of this share. It was found that a market multiple can be used to find more attractive companies for investors on the Warsaw Stock Exchange (Rutkowska-Ziarko, Gęstwicki, Williamson, 2015). On other hand, selecting underpriced companies is not enough for building an effective portfolio. Markowski and Rutkowska-Ziarko (2011) have found that a Markowiz portfolio outperforms simple diversification for Polish capital market. Thus, it is important to combine the Markowitz model with information about the current value of a market multiple. Loughran and Wellman (2011) analyzed a broad sample of non-financial firms from NYSE, AMEX, NASDAQ. They found that companies with low levels of market multiples appeared to have higher stock returns than companies with high levels of market multiples.

As for the book to market ratio (BM), the price of one ordinary share is related to the company's book value, calculated per one ordinary share. Therefore, this market multiple represents the firm's book value relative to its market value:

$$
B M=\frac{\text { book value of the company }}{\text { market value of the company }}=\frac{\text { book value per share }}{\text { price of the share }} .
$$

A positive relationship between the book to market ratio and average returns was described by Rosenberg, Reid and Lanstein (1985). This relationship was also proved for Japanese stocks (Chan, Hamao, and Lakonishok 1991). Based on this research, Fama and French (1992) suggested that book to market would be a significant factor describing the variability of stock returns. They proposed a three-factor model, which explains the returns on capital market with three factors: excess rate of return relative to the market portfolio, company's size and book to market ratio. This model was positively verified on a sample of US stocks.

As in the case of all market multiples, the book to market ratio is an additive measure. If we denote the book to market ratio of stock $i$ by $B M_{i}$, then the value of this measure for the whole portfolio is given by the following formula

$$
B M_{P}=\sum_{i=1}^{n} x_{i} B M_{i} .
$$

With the introduction of $B M_{P}$, we have three criteria for assessing an investment: expected return, risk and fundamental value. One of the methods for obtaining a portfolio which is efficient with respect to all three criteria is to solve a problem of minimizing the variance of a portfolio with constrains on the two other criteria. This leads to the following optimization problem

$$
\operatorname{minimize} \sum_{i=1}^{n} \sum_{j=1}^{n} x_{i} x_{j} \operatorname{cov}_{i j}
$$

with respect to

$$
\begin{aligned}
& \sum_{i=1}^{n} x_{i} \mu_{i} \geq \gamma \\
& \text { and } \\
& \sum_{i=1}^{n} x_{i} B M_{i} \geq B M_{\gamma},
\end{aligned}
$$

where $\gamma$ is the target rate of return and $B M_{\gamma}$ is the required by the investor minimal book value for one monetary unit of the total invested wealth. Of course, there is an additional condition that $\sum_{i=1}^{n} x_{i}=1$. 


\section{The analytical solution of the portfolio problem}

Let $\Sigma$ be a covariance matrix of returns, i.e.

$$
\Sigma=\left[\begin{array}{ccc}
\operatorname{cov}_{11} & \cdots & \operatorname{cov}_{1 n} \\
\vdots & \ddots & \vdots \\
\operatorname{cov}_{1 n} & \cdots & \operatorname{cov}_{n n}
\end{array}\right]
$$

Define the following vectors: $\mu=\left(\mu_{1}, \ldots, \mu_{n}\right)^{T}, z=\left(B M_{1}, \ldots, B M_{n}\right)^{T}$ and let $e$ be a column vector of length $n: e=(1, \ldots, 1)^{T}$. Using the vector notation, the optimization problem (4)-(6) can be expressed as follows:

$$
\text { minimize } \frac{1}{2} x^{T} \Sigma x
$$

with respect to

$$
\begin{aligned}
& x^{T} e=1, \\
& x^{T} \mu \geq \gamma
\end{aligned}
$$

and

$$
x^{T} z \geq B M_{\gamma} \text {. }
$$

The Kuhn-Tucker conditions for the problem (7)-(9) are as follows

$$
\Sigma x=\lambda_{1} e+\lambda_{2} \mu+\lambda_{3} z
$$

where $\lambda_{2}, \lambda_{3} \geq 0$, with the complementary conditions

$$
\begin{aligned}
& \lambda_{2}\left(x^{T} \mu-\gamma\right)=0, \\
& \lambda_{3}\left(x^{T} z-B M_{\gamma}\right)=0 .
\end{aligned}
$$

Assuming that the covariance matrix is nondegenerate (as it is done in practice), it follows from equation (11) that the solution has the following form:

$$
x=\lambda_{1} \Sigma^{-1} e+\lambda_{2} \Sigma^{-1} \mu+\lambda_{3} \Sigma^{-1} z .
$$

We have to consider several cases. To simplify the notation, we define the following symbols. Let

$$
\begin{aligned}
& g_{11}=e^{T} v^{1}, g_{12}=e^{T} v^{2}, g_{13}=e^{T} v^{3}, g_{22}=\mu^{T} v^{2}, \\
& g_{23}=\mu^{T} v^{3}, g_{33}=z^{T} v^{3},
\end{aligned}
$$

where

$$
v^{1}=\Sigma^{-1} e, \quad v^{2}=\Sigma^{-1} \mu, \quad v^{3}=\Sigma^{-1} z
$$

Firstly, assume that $\lambda_{2}=\lambda_{3}=0$. From complimentary conditions (12) and (13) it emerges that only condition (8) must be satisfied as equality. By inserting solution (11) with $\lambda_{2}=\lambda_{3}=0$ into (8), we obtain the solution

$$
\tilde{x}^{1}=\frac{1}{g_{11}} \Sigma^{-1} e .
$$

The minimal variance in this case equals

$$
\sigma_{1}^{2}=\frac{1}{g_{11}^{2}}
$$


In a case when $\lambda_{2}>0, \lambda_{3}=0$, the optimal solution condition (8) is fulfilled and condition (9) holds as an equation, which gives a set of equations

$$
\begin{aligned}
& \lambda_{1} g_{11}+\lambda_{2} g_{12}=1, \\
& \lambda_{1} g_{12}+\lambda_{2} g_{22}=\gamma .
\end{aligned}
$$

After some transformations, one can write the solution of this system as

$$
\tilde{x}^{12}=\left(1-\alpha_{12}\right) \tilde{x}^{1}+\alpha_{12} \frac{v^{2}}{g_{12}}
$$

where

$$
\alpha_{12}=\frac{g_{12}\left(\gamma g_{11}-g_{12}\right)}{g_{11} g_{22}-g_{12}^{2}}
$$

The variance of the portfolio in this solution equals $\sigma_{12}^{2}=\sigma_{1}^{2}+\Delta \sigma_{12}^{2}$, where

$$
\Delta \sigma_{12}^{2}=\frac{\left(\gamma g_{11}-g_{12}\right)^{2}}{g_{11}}
$$

The case $\lambda_{2}=0, \lambda_{3}>0$ is analogous to the last one. The optimal solution satisfies conditions ( 8 ) and (10) as equations. The solution can be expressed as

$$
\tilde{x}^{13}=\left(1-\alpha_{13}\right) \tilde{x}^{1}+\alpha_{13} \frac{v^{3}}{g_{13}},
$$

where

$$
\alpha_{13}=\frac{g_{13}\left(E P_{\gamma} g_{11}-g_{13}\right)}{g_{11} g_{33}-g_{13}^{2}} .
$$

The growth of variance when switching from $\tilde{x}^{1}$ to $\tilde{x}^{13}$ equals

$$
\Delta \sigma_{13}^{2}=\frac{\left(E P_{\gamma} g_{11}-g_{13}\right)^{2}}{g_{11}}
$$

The last case is when $\lambda_{2}>0, \lambda_{3}>0$. In this case, all conditions (8)-(10) must be fulfilled as equalities, which brings us to the following set of equations

$$
\lambda G=a,
$$

where $\lambda$ is the vector of multipliers $\lambda=\left(\lambda_{1}, \lambda_{2}, \lambda_{3}\right)^{T}, a=\left(1, \gamma, B M_{\gamma}\right)^{T}$ and matrix $G$ is

$$
G=\left[\begin{array}{lll}
g_{11} & g_{12} & g_{13} \\
g_{12} & g_{22} & g_{23} \\
g_{13} & g_{23} & g_{33}
\end{array}\right] .
$$

The optimal solution to the problem (4)-(7) with all conditions fulfilled as equation can be expressed as follows:

$$
\tilde{x}^{123}=\lambda_{1} v^{1}+\lambda_{2} v^{2}+\lambda_{3} v^{3}, \text { where } \quad \lambda=G^{-1} a .
$$

These derivations lead to the following algorithm for finding the optimal solution of the problem (4)(6):

1. Compute vector $\tilde{x}^{1}$ and check if it fulfills conditions (5) and (6). If so, this is the optimal solution.

2. Otherwise, calculate $\Delta \sigma_{12}^{2}$ and $\Delta \sigma_{13}^{2}$. Choose the smaller value: let it be $\Delta \sigma_{1 k}^{2}$. 
Compute vector $\tilde{x}^{1 k}$ and check if it fulfills conditions (5) and (6). If so, this is the optimal solution. Otherwise the optimal solution is vector $\tilde{x}^{123}$.

\section{Empirical results}

In order to present computations of effective portfolios according to the augmented approach, we considered portfolios of the stock of 20 largest and most liquid companies listed on the Warsaw Stock Exchange. The sample includes all WIG20 companies. The computations are based on quarterly returns calculated on daily closing prices in the period starting from the beginning of August 2013 and ending on 7 February 2020. Returns were computed as relative increases in prices according to the formula:

$$
r_{i t}=\frac{P_{i t+s}-P_{i t}}{P_{i t}} \cdot 100 \%,
$$

where $r_{i t}$ is the rate of return on security $i$ at time $t, s$ is the length of investment horizon (in our case one month) expressed in days and $P_{i t}$ is the quoted price of security $i$ at time $t$.

Financial indicators for each company were calculated based on annual financial reports for the years from 2012 to 2018. For each company in the sample, we computed the book to market ratio for all trading days. The expected return and standard deviations were calculated based on time series of returns.

Firstly, we considered possible effective portfolios which can be created on the last day of the considered period. It is worth noticing that we took into account about 1700 trading days in which portfolios were created. In every time unit, four types of portfolios were built, and their realized returns were calculated. The aim was to evaluate the practical usefulness of the proposed method for investors in the Polish capital market. To make these computations, we developed a specialized software application in $\mathrm{R}$ package, which allowed us to solve optimization problems, create several thousands of optimal portfolios, and compare their performance.

Table 1 contains information concerning estimations of the expected return, risk and book to market ratio for all companies as of 7 February 2020. It is only an example of one trading day from the 1700 days included in our research. Characteristics of rates of return (i.e. expected return and standard deviation) were estimated based on the last 400 returns. Book to market ratios were calculated on the basis of closing prices on the last trading day. 
Table 1: Mean return, risk and book to market ratio (BM)

\begin{tabular}{|l|r|r|r|r|}
\hline Company & Mean (\%) & $\begin{array}{r}\text { Standard } \\
\text { deviation (\%) }\end{array}$ & BM & $\begin{array}{r}\text { Number of } \\
\text { observations }\end{array}$ \\
\hline ACP & 2.80 & 6.25 & 0.89 & 400 \\
\hline ATT & -1.49 & 14.70 & 1.76 & 400 \\
\hline BDX & 2.07 & 11.87 & 0.13 & 400 \\
\hline CAR & -0.37 & 7.95 & 0.42 & 400 \\
\hline CCC & -4.38 & 12.42 & 0.26 & 400 \\
\hline CDR & 4.11 & 11.06 & 0.03 & 400 \\
\hline CIE & -2.17 & 10.43 & 0.66 & 400 \\
\hline CMR & 2.24 & 6.92 & 0.51 & 400 \\
\hline CPS & 1.06 & 6.07 & 0.63 & 400 \\
\hline ENA & -1.04 & 11.51 & 4.02 & 400 \\
\hline EUR & -0.17 & 10.69 & 0.37 & 400 \\
\hline GTC & 0.57 & 5.52 & 0.96 & 400 \\
\hline KER & -0.13 & 7.09 & 0.29 & 400 \\
\hline KGH & 0.77 & 8.93 & 0.97 & 400 \\
\hline KTY & 0.26 & 7.53 & 0.18 & 400 \\
\hline LPP & -0.09 & 7.05 & 0.19 & 400 \\
\hline LTS & 2.59 & 8.65 & 0.70 & 400 \\
\hline PGE & -1.04 & 10.56 & 3.13 & 400 \\
\hline PGN & -1.84 & 7.93 & 1.34 & 400 \\
\hline PKN & 0.25 & 8.76 & 0.97 & 400 \\
\hline
\end{tabular}

Source: own calculations

The BM of the companies under research varied from 0.03 to 4.02 . The lowest value, 0.03 , was for company CD Project S.A. (CDR). This is a software company producing computer games with a small amount of own assets. Its book to market ratio decreased from 0.22 in 2012 to 0.03 in 2020, mainly due to an exceptional increase in its stock prices.

To check the dependences between the criteria for measuring performance of the portfolio we have estimated correlation coefficients from the whole sample (from August 2013 till 7 February 2020). Too high correlation (positive or negative) between the values of the criteria would mean that there is no trade-of between them and the portfolio problem is ill-posed. The book to market ratios of the companies were negatively correlated with the mean returns (correlation coefficient -0.288 ) and positively correlated with standard deviation of returns (correlation coefficient 0.291 ). There was a negative correlation between the mean return and risk measured with variance (correlation coefficient -0.360 ). The values correlation coefficients are moderate and we can consider trade-offs between different criteria.

The problem of portfolio choice in this situation is a trade-off between risk and the two other criteria. We seek a portfolio which minimizes risk. However, low-risk portfolios tend to have lower expected return. On the other hand, if we assume higher requirements on the mean return of a portfolio, the solution will have a lower book to market ratio. Figure 1 depicts the efficient frontier for the three- 
criteria portfolio choice. Each point in the graph represents a solution to problem (4)-(6) for a different combination of the required expected return and required level of BM.

\section{Figure 1: Effective frontier for the portfolio problem with three criteria}

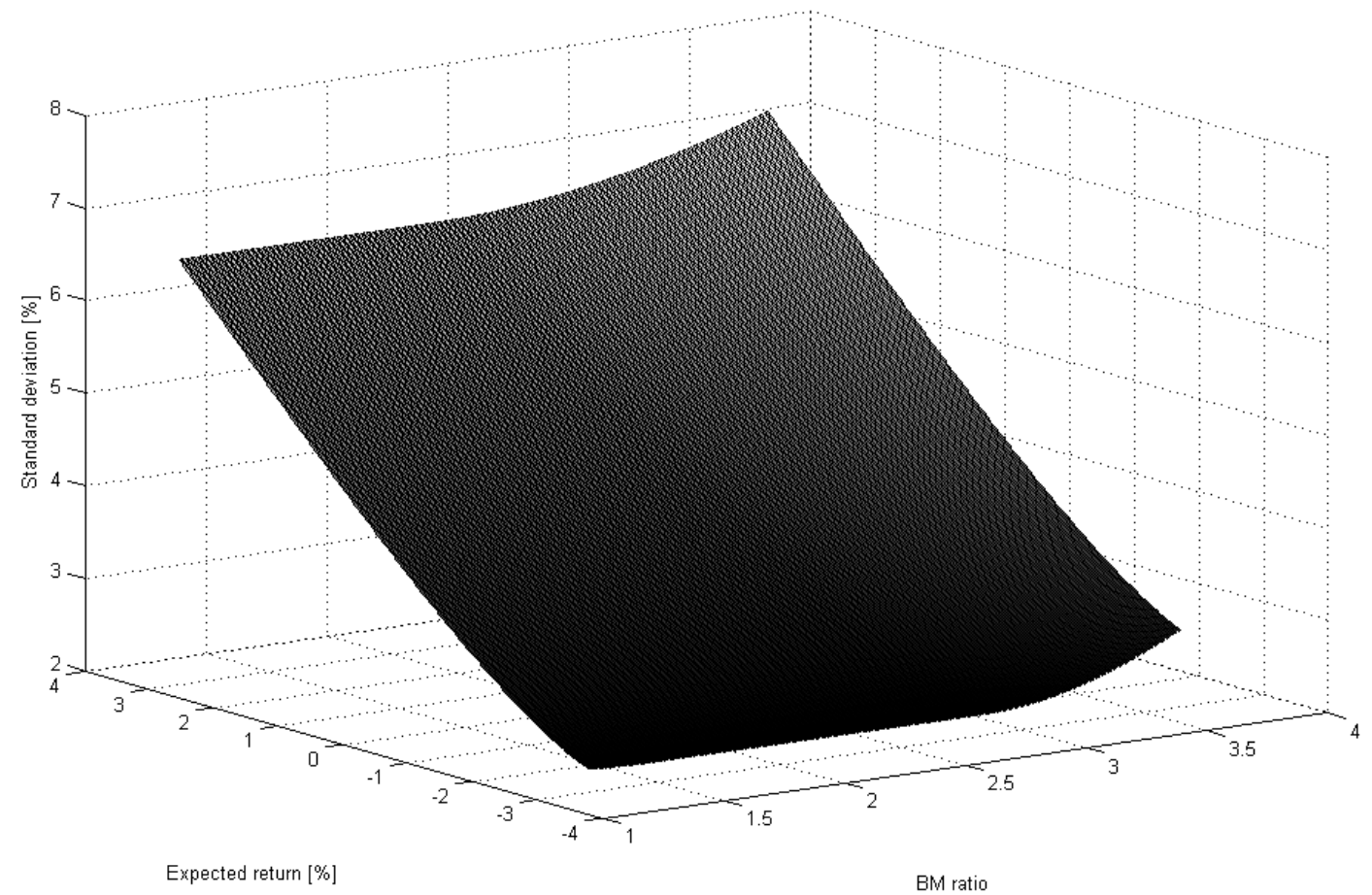

Source: own study

In order to analyze the impact of fundamental values of companies in which one is willing to invest on the trade-off between expected return and risk, we determined the shape of efficient frontiers for various values of the required $\mathrm{BV}$ ratio. Using the algorithm proposed in section 3 , we calculated effective portfolios for $B M_{\gamma}$ at the levels of 1.23, 1.90, 2.56 and 3.23. The results are depicted in Figure 2. The graph shows that higher levels of required the book to market ratio move the effective frontier upwards. The restriction connected with the BM ratio is less important for lower levels of the required BM ratio, as the required profitability of expected return grows, and it does not apply to the highest levels of the expected rate of return. 
Figure 2: Effective frontiers for different values of the book to market ratio

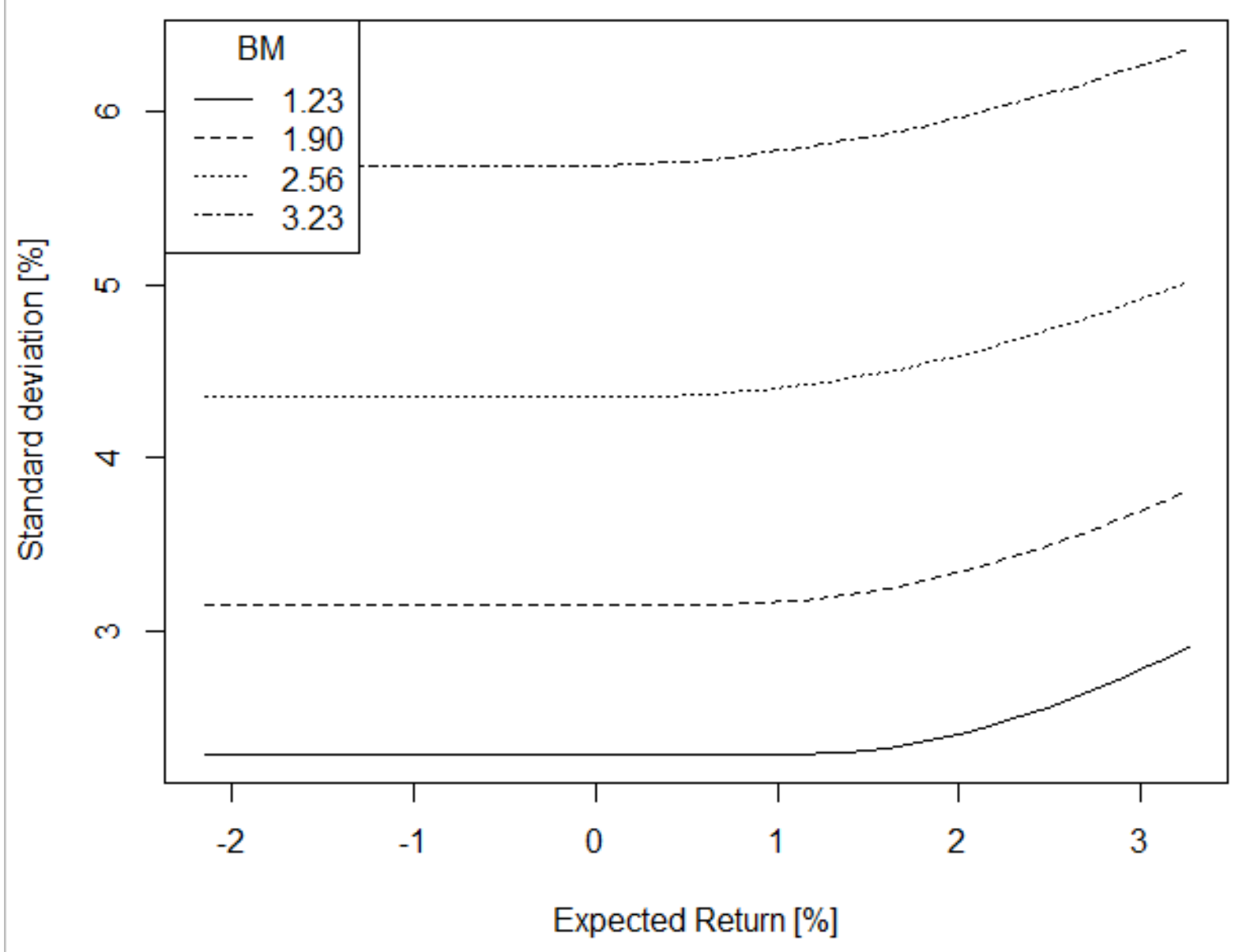

Source: own study

In order to compare the investments according to the fundamental method (i.e. with the book to market ratio as the third criterion) with ones derived in line with the classical approach, we performed the following calculations. We calculated several portfolios using both methods. Data for portfolio calculations were estimated based on a moving frame of the length of 400 trading days. The first frame started on 2013-04-03 and the last one began on 2020-02-05. There were 1705 frames in total. For each frame, we estimated all parameters required in both investment problems. Then, we considered investments for one moth starting on the next trading day. In each case, we considered four portfolios. The first one was the solution of a classical problem with the required rate of return equal to expected rates of return of all stock. The next three were solutions of the problem including the fundamental criterion with the same required rate of return and values of the book to market ratio equal $1.28,2.12$ and 2.97 , respectively. The numbers are $30 \%, 50 \%$ and $70 \%$ percentiles of the observed book to market values of the considered stocks. In each case, we assumed that the expected return of the portfolio should be equal to the actual mean return of the stocks in the portfolio. Then, we checked calculated realized returns for each of these portfolios.

For each kind of portfolio, we calculated the mean return, standard deviation and cumulated return from the whole period of our study. Besides, we verified the percentage of cases in which return 
from a specific portfolio exceed returns from the classical portfolio. The results were presented in Table 2. Portfolio P1 is the classical Markovitz portfolio with minimal variation (under the condition that the expected value is equal to the observed mean return). Portfolios P2, P3 and P4 were constructed with the additional restriction on values of the book to market ratio $(1.28,2.12$ and 2.97, respectively)

It transpires from all cases that the results from the portfolios with the BM criterion had higher mean returns and lower risk. In two of them, the cumulated return values were higher.

\section{Table 2. The results (ex post, realized returns)}

Source: own calculations

\begin{tabular}{|l|c|c|c|c|}
\hline Portfolio & $\begin{array}{c}\text { Mean } \\
\text { return }\end{array}$ & Std & Exceedings & $\begin{array}{c}\text { Cum. } \\
\text { return }\end{array}$ \\
\hline P1 & 1.05 & 6.21 & 0 & 1.55 \\
\hline P2 & 1.35 & 6.71 & $55.52 \%$ & 1.95 \\
\hline P3 & 1.19 & 9.55 & $51.58 \%$ & 1.67 \\
\hline P4 & 1.11 & 13.49 & $51.04 \%$ & 1.32 \\
\hline
\end{tabular}

\section{Conclusions}

In the paper, we propose an algorithm for constructing a portfolio of assets where three criteria are considered: potential profitability of the investment (measured with expected return), risk (measured with variance of returns) and economic situation of companies in the portfolio (given by the book to market ratio). The algorithm for finding effective portfolios inclusive of all the three criteria is based on analytical solutions of optimization problems. We have demonstrated that the algorithm is effective and allows one to construct efficient portfolios with minimal computational effort.

The proposed algorithm enabled us to determine the effective frontier (i.e. the tradeoff between expected return and risk) for several levels of requirements concerning fundamental values of companies whose stocks are in a portfolio. The empirical research results for the major companies traded on the Warsaw Stock Exchange reveal that inclusion of the book to market ratio as an additional criterion in creating a portfolio can lead to better performance.

\section{Reference}

Ball R. (1992) The Earnings-Price Anomaly. Journal of Accounting and Economics. vol. 15, pp. 319-345. DOI: 10.1016/0165-4101(92)90023-U

Ballestero, E.; Bravo, M.; Perez-Gladish, B.; Arenas-Parra, M.; Pla-Santamaria, D. (2012) Socially Responsible Investment: a Multicriteria Approach to Portfolio Selection Combining Ethical and Financial Objectives. European Journal of Operational Research. vol. 216, pp. 487-494. DOI: 10.1016/j.ejor.2011.07.011

Basu S. (1977) Investment Performance of Common Stocks in Relation to Their Price-earnings Ratios: A Test of the Efficient Market Hypothesis. Journal of Finance. vol. 3, pp. 663-682. DOI: 10.2307/2326304

Bilbao-Terol, A.; Arenas-Parra, M.; Cañal F.; Bilbao-Terol, C. (2013) Selection of Socially Responsible Portfolios Using Hedonic Prices. Journal of Business Ethics. vol. 115, pp. 515-529. DOI: 10.1007/s10551-012-1411-6 
Briec,W.; Kerstens, K.; Jokund, O. (2007) Mean-Variance-Skewness Portfolio Performance Gauging: A General Shortage Function and Dual Approach. Management Science. vol. 53, pp. 135-149. DOI: $10.1287 / \mathrm{mnsc} .1060 .0596$

Chan, L. K. C., Hamao, Y., and Lakonishok, J. (1991). Fundamentals and Stock Returns in Japan. The Journal of Finance. vol. 46. pp. 1739-1764. DOI: 10.2307/2328571

Doumpos, M.; Zopounidis, C. (2014) Multicriteria Analysis in Finance. Springer, Heidelberg, New York.

Fabozzi, F.J., Focardi, S., Jonas, C. (2007) Trends in Quantitative Equity Management: Survey Results. Quantitative Finance. vol. 7, pp. 115-122. DOI: 10.1080/14697680701195941

Fama, E. F., \& French, K. R. (1992). The Cross-Section of Expected Stock Returns. Journal of Finance. vol. 47, pp. 427-465. DOI: 10.2307/2329112

Fama, E. F., \& French, K. R. (2015). A five-factor asset pricing model. Journal of Financial Economics. vol. 116, pp. 1-22. DOI: 10.1016/j.jfineco.2014.10.010

Fama, E. F., \& French, K. R. (2017). International tests of a five-factor asset pricing model. Journal of Financial Economics. vol. 123, pp. 441-463. DOI: 10.1016/j.jfineco.2016.11.004

Jacobs, B.; Levy, K. (2013) Leverage aversion, efficient frontiers, and the efficient region. Journal of Portfolio Management. Vol. 39, pp. 54-64. DOI: 10.2139/ssrn.2149610

Kolm, P.; Tütüncü, R.; Fabozzi, F. (2014) 60 Years of Portfolio Optimization: Practical Challenges and Current Trends. European Journal of Operational Research. Vol. 234, pp. 356-371. DOI: 10.1016/j.ejor.2013.10.060

Lam, K. S. K. (2002). The relationship between size, book-to-market equity ratio, earnings-price ratio, and return for the Hong Kong stock market. Global Finance Journal. vol. 13, pp. 163-179. DOI: 10.1016/S1044-0283(02)00049-2

Lo, A.; Petrov, C.; Wierzbicki, M. (2003): Its 11pm-Do You Know Where Your Liquidity Is? The MeanVariance-Liquidity Frontier. Journal of Investment Management. Vol. 1, pp. 55-93. DOI: 10.1142/9789812700865_0003

Loughran, T.; Wellman, J. (2011) New evidence on the relation between the enterprise multiple and average stock returns. Journal of Financial and Quantitative analysis. vol. 46, no. 6, pp 1629-1650. DOI: 10.2139/ssrn.1481279

Kliber P. , Rutkowska-Ziarko A.(2018). An analytical method for construction of a fundamental portfolio. Prace Naukowe Uniwersytetu Ekonomicznego we Wrocławiu 63 (2), pp. 25-36 ; DOI: 10.15611/pn.2019.2.03

Markowitz, H. (1952) Portfolio selection. Journal of Finance, vol. 7, pp. 77-91. DOI: 10.2307/2975974

Markowitz, H. (1959) Portfolio Selection: Efficient Diversification of Investments. John Wiley and Sons, New York.

Markowski L., Rutkowska-Ziarko A., The effectiveness of simple diversification in comparition to Markowiz portfolio theory, Olsztyn Economic Journal 6(1) 2011.pp. 143-154.

Pośpiech, E.(2019). Effective Portfolios - An Application of Multi-Criteria and Fuzzy Approach. Folia Oeconomica Stetinesia. vol. 18, pp. 126-139. DOI: 10.2478/foli-2019-0009

Rodríguez, R.; Luque, M.; González, M. (2011) Portfolio Selection in the Spanish Stock Market by Interactive Multiobjective Programming. TOP. vol. 19, pp. 213-231. DOI: 10.1007/s11750-010-0139-7

Rosenberg, B., Reid, K., \& Lanstein, R. (1985). Persuasive evidence of market inefficiency. The Journal of Portfolio Management. vol. 11, pp. 9-16. DOI: 10.3905/jpm.1985.409007

Rutkowska-Ziarko, A. (2013) Fundamental portfolio construction based on Mahalanobis distance. In: Algorithms from and for Nature and Life, Studies in Classification, Data Analysis, and Knowledge 
Organization. Springer International Publishing Switzerland, pp. 417-426. DOI: 10.1007/978-3-31900035-0_42

Rutkowska-Ziarko A.; Garsztka P. (2014) Diversification of risk of a fundamental portfolio based on semivariance. Poznań University of Economics Review. vol. 14, pp. 80-96.

Rutkowska-Ziarko A., Gęstwicki F., Williamson T., Size effect and efficiency of investment strategy based on market multiples. Acta Scientarum Polonorum. Oeconomia 15 (1) 2016,pp. 99-111.

Sharpe, W.F. (1963) A simplified model for portfolio analysis. Management Science. vol. 9, pp. 277-293. DOI: $10.1287 / \mathrm{mnsc} .9 .2 .277$

Steuer, R.; Qi, Y.; Hirschberger, M. (2007) Suitable-portfolio investors, nondominated frontier sensitivity, and the effect of multiple objectives on standard portfolio selection. Annals of Opererations Research. vol. 152, pp. 297-317. DOI: 10.1007/s10479-006-0137-1

Tarczyński, W. (2002) Portfel fundamentalny papierów wartościowych [Fundamental Portfolio of Assets]. Polish Economic Editorial Office (PWE). Warsaw. [in Polish]

Xidonas, P.; Mavrotas, G.; Psarras, J. (2010) Equity Portfolio Construction and Selection Using Multiobjective Mathematical Programming. Journal of Global Optimization. vol. 47, pp. 185-209. DOI: 10.1007/s10898-009-9465-4

Zaremba, A., Czapkiewicz, A. (2017). Digesting anomalies in emerging European markets: A comparison of factor pricing models. Emerging Markets Review. vol. 31, pp.1-15. DOI: 10.1016/j.ememar.2016.12.002 